\title{
Lobular Panniculitis due to Borrelia burgdorferi infection mimicking subcutaneous panniculitis-like T-Cell Lymphoma
}

\author{
Kempf, Werner ; Kazakov, Dmitry V ; Kutzner, Heinz
}

\begin{abstract}
ABSTRACT:: The authors present an unusual case of lobular panniculitis caused by Borrelia burgdorferi senso latu infection in a 56-year-old man. It presented clinically as a solitary subcutaneous nodule. Histopathologically, the lesion resembled subcutaneous panniculitis-like T-cell lymphoma by manifesting atypically appearing lymphocytes with cytotoxic phenotype. B. burgdorferi etiology was proven by positive polymerase chain reaction and serology and positive response to antibiotics.
\end{abstract}

DOI: https://doi.org/10.1097/DAD.0b013e31827132cb

Posted at the Zurich Open Repository and Archive, University of Zurich

ZORA URL: https://doi.org/10.5167/uzh-67826

Journal Article

Accepted Version

Originally published at:

Kempf, Werner; Kazakov, Dmitry V; Kutzner, Heinz (2013). Lobular Panniculitis due to Borrelia burgdorferi infection mimicking subcutaneous panniculitis-like T-Cell Lymphoma. American Journal of Dermatopathology, 35(2):e30-3.

DOI: https://doi.org/10.1097/DAD.0b013e31827132cb 


\section{The American Journal of Dermatopathology Lobular panniculitis due to Borrelia burgdorferi infection mimicking subcutaneous panniculitis-like T-cell lymphoma \\ --Manuscript Draft--}

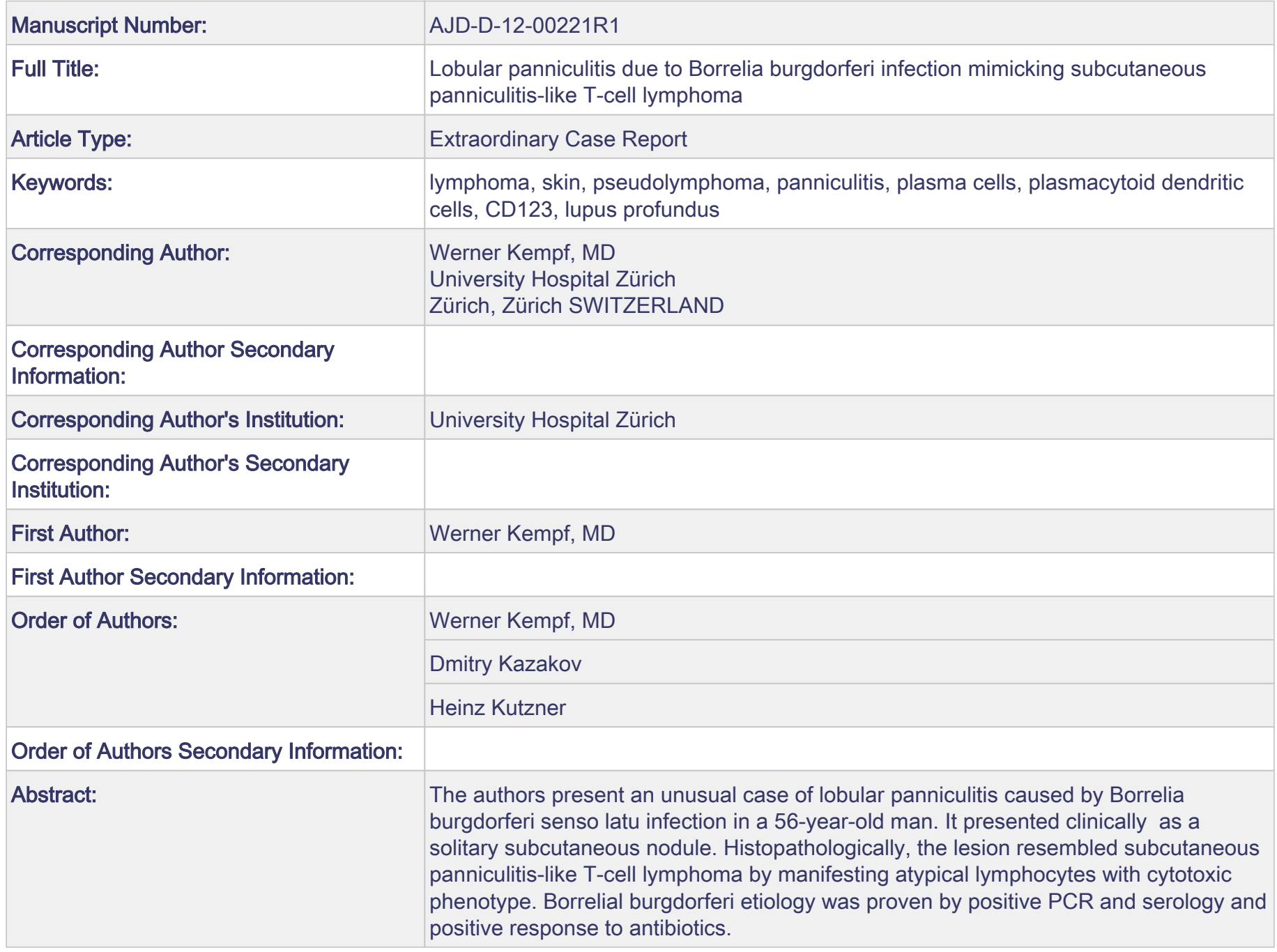


Omar Sangüeza, MD

Editor-in-Chief

American Journal of Dermatopathology

\section{Manuscript revision, AJD-D-12-00221}

\section{August 21, 2012}

Dear Dr Sangüeza, dear Omar

Enclosed please find the revised version of our manuscript, titled "Lobular panniculitis due to Borrelia burgdorferi infection mimicking subcutaneous panniculitis-like T-cell lymphoma" and our replies to the comments of the reviewers. All corrected areas are marked red in the revised version for your convenience.

We thank you and both referees for your time and consideration to publish the above paper in your journal.

Sincerely yours

Werner Kempf, MD

Werner Kempf, MD, Kempf und Pfaltz, Histologische Diagnostik

Seminarstrasse 1, CH-8042 Zürich Switzerland

Phone: +41-43-443 1177 Fax: +41-43-443 1178 Email: werner.kempf@access.uzh.ch 
Reviewer \#1: This is an interesting and well-written case report involving a potential diagnostic dilemma. The spectrum of cutaneous manifestations of Borrelia infections continues to expand, and this example is particularly important for a dermatopathologist to be familiar with, as the difference in treatment is potentially highly significant. (i.e. antibiotics versus chemotherapy or other cancer therapies.) The images are clear, with excellent descriptions. In addition, the descriptions of the morphologic features, differential diangosis, and diagnostic modalities and results are very thorough. Excellent manuscript!

\section{Our reply:}

We thank the reviewer for his/her time and high estimation of our manuscript.

Reviewer \#2: excellent well written paper of an unusual phenomenon. while the cells are not particularly atypical, i can see how the low power image brings up subcutaneous lymphomas and lupus profundus in the differential. I only have one comment, regarding pictures of betaF1. i can't tell from the picture how many cells are staining and note that your manuscript implied not all $\mathrm{t}$ cells expressed tcrbeta. were the rest gamma-delta cells? the figure legends should probably included magnifications.

\section{Our reply:}

We thank the reviewer for his/her time and high estimation of our manuscript.

As suggested by the reviewers we have added percentage of beta F1 lymphocytes. We have also stained for TCR gamma/delta to include this information. The precise magnification of the images is difficult to specify, as we scanned them and then cropped out the included parts, and this methods permits no tracking of the precise magnifications. However, we trust that the figures are informative as are. Thank you. 
Lobular panniculitis due to Borrelia burgdorferi infection mimicking subcutaneous panniculitis-like T-cell lymphoma

\section{Authors:}

Werner Kempf $^{1}$, Dmitry V. Kazakov ${ }^{2}$, Heinz Kutzner ${ }^{3}$

\section{Institutions:}

${ }^{1}$ Kempf und Pfaltz, Histologische Diagnostik, Zürich, Switzerland;

${ }^{2}$ Dept. of Pathology, Faculty of Medicine in Pilsen, Charles University in Prague, Czech Republic,

${ }^{3}$ Dermatopathologische Gemeinschaftspraxis Friedrichshafen, Germany

Short title: Panniculitis in borreliosis

\section{Corresponding author:}

Werner Kempf, MD, Kempf und Pfaltz, Histologische Diagnostik

Seminarstrasse 1, CH-8042 Zürich Switzerland

Phone: +41-43-443 1177 Fax: +41-43-443 1178 Email: werner.kempf@access.uzh.ch

The authors have no conflicts of interests to declare 


\begin{abstract}
The authors present an unusual case of lobular panniculitis caused by Borrelia burgdorferi senso latu infection in a 56-year-old man. It presented clinically as a solitary subcutaneous nodule. Histopathologically, the lesion resembled subcutaneous panniculitis-like T-cell lymphoma by manifesting atypical lymphocytes with cytotoxic phenotype. Borrelial burgdorferi etiology was proven by positive PCR and serology and positive response to antibiotics.
\end{abstract}

Key words: lymphoma, skin, pseudolymphoma, panniculitis, plasma cells, plasmacytoid dendritic cells, CD123, lupus profundus 
Borreliosis, or Lyme disease is a multifocal world-wide disease caused by a group of related spirochetes Borrelia burgdorferi (sensu lato) which are transmitted by specific Ixodes spp ticks. (1) Lyme disease is the most common tick-borne infectious disease in North America where it is caused by the only species of Borrelia, namely Borrelia burgdorferi sensu stricto. In contrast, in Europe, at least 5 species of Borrelia (B burgdorferi (sensu stricto), Borrelia afzelii, Borrelia garinii, Borrelia spielmanii, and Borrelia bavariensis) can cause the human disease, leading to a wider variety of possible clinical presentations, of which the most common ones include erythema migrans, lymphocytoma cutis and acrodermatitis chronica atrophicans. (2), (3), (4), (5), (6), (7), (8) Panniculitis is an extremely rare presentation of borreliosis, described to date only in a handful of cases. (9), (10), (11) We present a patient with Borreliosis in whom an initial biopsy revealed lobular panniculitis with a dense infiltrate containing atypical cells with cytotoxic phenotype thus closely mimicking subcutaneous panniculitis-like T-cell lymphoma, a manifestation not previously reported to our knowledge.

\section{Clinical case report, treatment and follow-up}

A 56-year-old man presented with a subcutaneous infiltration on the right chest wall and an erythematous lesion on the right arm that had appeared prior to occurrence of the subcutaneous nodule. He was otherwise healthy, and, specifically no B symptoms were reported. After the diagnosis of borreliosis (vide infra), the patient was administered doxicycline $100 \mathrm{mg}$ twice a day for 3 weeks with complete remission. The patient is alive with no evidence of the disease 12 years after the treatment and no recurrence of the skin disease was seen during the follow-up period.

\section{Histopathological findings}

The biopsy specimen from the subcutaneous lesion revealed a dense lymphocytic infiltrate mostly involving the lobules of the subcutis, with little, if any, extension into the fibrous septa, a pattern consistent with lobular panniculitis. (12), (13) The lymphocytes were small to medium sized cells; some of them manifested slight to moderate nuclear polymorphism and hyperchromatic somewhat irregular nuclei with few mitotic figures. There was so-called rimming of the cells around the adipocytes. (14) Admixed with the lymphoid cells were numerous histiocytes. Plasma cells were also seen, both dispersed and forming small clusters. Focally, necrotic adipocytes lacking nuclei as well as areas with lipophagic necrosis were recognized. There were no vascular changes. On serial sections, focal involvement of the deep reticular dermis was observed, and in this area, there were occasional lymphocytic debris in 
the infiltrate and discreet deposits of mucin between collagen bundles. There were no lymphoid follicles with germinal centers. The epidermis was uninvolved.

The biopsy specimen from the erythematous lesion yielded mild spongiosis and sparse perivascular lymphoid infiltrates containing occasional plasma cells.

\section{Immunohistochemical findings}

Most lymphocytes in the specimen from the nodular lesion expressed T-cell markers, with a marked predominance of CD8+ TIA-1+ cells over CD4+ elements. Beta F1 was expressed by the majority of T cells $(\sim 70-80 \%)$. Staining for TCR gamma/delta revealed occasional cells $(<10 \%)$. CD56 and CD30 were negative. CD138 and CD123 highlighted plasma cells and plasmacytoid dendritic cells, respectively. Plasma cells displayed no immunoglobulin light chain restriction. CD68 highlighted the presence of numerous histiocytes.

\section{Molecular biology findings}

Borrelia sp. DNA was detected by nested PCR in the biopsy tissue from the subcutaneous nodule lesion. The results of the PCR for Borrelia for the erythematous lesion were inconclusive because of poor DNA quality. Molecular studies revealed no monoclonal rearrangement of T-cell receptor gamma genes. No EBV DNA was found.

\section{Serological tests}

Borrelia serology was positive. ANA and dsDNA were negative.

\section{Discussion}

Panniculitis has very rarely been reported as manifestation of borreliosis. Acute septal panniculitis as in a patient with Lyme disease was documented by Kramer et al in 1986. (9) Viljanen et al described a patient with multiple relapsing skin nodules, the biopsy of which revealed involvement of the subcutis, and, as far as one can judge from the description and enclosed illustration, it was lobular panniculitis. However, in contrast to our case, the infiltrate was focal and sparse. (10) Hassler presented 2 cases with borreliosis referring to their subcutaneous lesions as nodular panniculitis. (11)

In our case, the dense lobular infiltrate composed of slightly atypical lymphocytes occasioned a great resemblance to a malignant lymphoma involving the subcutis. The differential 
diagnosis included lymphomas that can present with features of lobular panniculitis, namely subcutaneous panniculitis-like T-cell lymphoma (SPLTCL), subcutaneous gamma/delta T-cell lymphoma, and extranodal T/NK-cell lymphoma. (15), (16), (17), (18),

Additionally, lupus eythematotus panniculitis (lupus profundus) was a differential diagnostic consideration.

The above lymphomas were excluded by the immunophenotype and lack of clonal TCR rearrangements. SPLTCL is characterized by CD3+ CD4- CD8+ CD56- TIA-1+ granzyme $\mathrm{B}+$ betaF1+ cells. Cutaneous gamma/delta lymphoma with subcutaneous involvement manifest the following immunoprofile: CD3+, CD4-, CD8-, CD56+, TIA-1+, granzyme B +, betaF1-, and TCRdelta +. Extranodal T/NK-cell lymphoma usually manifests EBV positivity. Lupus panniculitis was also considered, especially taken into account the presence of focal mucin deposits in the dermis, nuclear debris and plasmacytoid dendritic cells. It is a rare (up to $3 \%$ ) manifestation of lupus eythematosus (LE), usually occurring in patients with discoid or systemic LE but also as an isolated phenomenon. Distinction between lupus panniculitis and SPLTCL may be very difficult, and in fact some authors suggested that the two entities may belong to a spectrum of disease. (21), (22) Magro et al introduced the term "subcutaneous T-cell lymphoid dyscrasia" to encompass these 2 diseases. (21), (23) Massone et al found that most useful histopathological criteria for distinguishing lupus panniculitis from SPLTCL are epidermal changes, lymphoid follicles with reactive germinal centers, clusters of B lymphocytes and mixed cell infiltrate with prominent plasma cells. (24) With regard to the latter, however, Willemze et al, in a large series, showed that patients with a concurrent or prior diagnosis of LE showed a considerable admixture of plasma cells not observed in the other cases of SPLTCL. (18)

Another interesting observation in our case along this line was the presence of clusters of CD123 + plasmacytoid dendritic cells. These have been suggested to represent a clue to the diagnosis of LE. Noteworthy, Pincus et al demonstrated CD123 + plasmacytoid dendritic cells in 5 patients with overlapping features of SPLTCL and LE. (22) Clusters of CD123+ plasmacytoid dendritic cells have recently been found in $100 \%$ cases of cutaneous marginal zone lymphoma, another entity variably associated with Borrelia burgdorferi infection. (25) Activation of plasmacytoid dendritic cells by an infectious agent (including Borrelia) has been suggested to be implicated in the pathogenesis of this lymphoma and its close mimic B-cell pseudolymphoma. (26) 
In conclusion, we have described an unusual manifestation of Borreliosis histopathologically imitating SPLTCL. This observation confirms previous observations that panniculitis might be a very rare form of borreliosis, and this disease can be added to the list of entities characterized by preferential or exclusive involvement of the subcutis. (12), (13) 
1. Steere AC, Grodzicki RL, Kornblatt AN, et al. The spirochetal etiology of Lyme disease. N Engl J Med 1983;308:733-40.

2. $\quad$ Stanek G, Wormser GP, Gray J, et al. Lyme borreliosis. Lancet 2012;379:461-73.

3. Malane MS, Grant-Kels JM, Feder HM, Jr., et al. Diagnosis of Lyme disease based on dermatologic manifestations. Ann Intern Med 1991;114:490-8.

4. Grange F, Wechsler J, Guillaume JC, et al. Borrelia burgdorferi-associated lymphocytoma cutis simulating a primary cutaneous large B-cell lymphoma. J Am Acad Dermatol 2002;47:530-4.

5. Colli C, Leinweber B, Mullegger R, et al. Borrelia burgdorferi-associated lymphocytoma cutis: clinicopathologic, immunophenotypic, and molecular study of 106 cases. J Cutan Pathol 2004;31:232-40.

6. Boudova L, Kazakov DV, Sima R, et al. Cutaneous lymphoid hyperplasia and other lymphoid infiltrates of the breast nipple: a retrospective clinicopathologic study of fifty-six patients. Am J Dermatopathol 2005;27:375-86.

7. Belousova IE, Nemcova J, Kacerovska D, et al. Atypical histopathological features in cutaneous lymphoid hyperplasia of the scrotum. Am J Dermatopathol 2008;30:407-8.

8. Mullegger RR, Glatz M. Skin manifestations of lyme borreliosis: diagnosis and management. Am J Clin Dermatol 2008;9:355-68.

9. Kramer N, Rickert RR, Brodkin RH, et al. Septal panniculitis as a manifestation of Lyme disease. Am J Med 1986;81:149-52.

10. Viljanen MK, Oksi J, Salomaa P, et al. Cultivation of Borrelia burgdorferi from the blood and a subcutaneous lesion of a patient with relapsing febrile nodular nonsuppurative panniculitis. J Infect Dis 1992;165:596-7.

11. Hassler D, Zorn J, Zoller L, et al. [Nodular panniculitis: a manifestation of Lyme borreliosis?]. Hautarzt 1992;43:134-8.

12. Requena L, Yus ES. Panniculitis. Part I. Mostly septal panniculitis. J Am Acad Dermatol 2001;45:163-83; quiz 184-6.

13. Requena L, Sanchez Yus E. Panniculitis. Part II. Mostly lobular panniculitis. J Am Acad Dermatol 2001;45:325-61; quiz 362-4.

14. Lozzi GP, Massone C, Citarella L, et al. Rimming of adipocytes by neoplastic lymphocytes: a histopathologic feature not restricted to subcutaneous T-cell lymphoma. Am J Dermatopathol 2006;28:9-12.

15. Grilli R, Soriano ML, Izquierdo MJ, et al. Panniculitis mimicking lupus erythematosus profundus: a new histopathologic finding in malignant atrophic papulosis (Degos disease). Am J Dermatopathol 1999;21:365-8.

16. Willemze R, Jaffe ES, Burg G, et al. WHO-EORTC classification for cutaneous lymphomas. Blood 2005;105:3768-85.

17. Burg G, Kempf W, Cozzio A, et al. WHO/EORTC classification of cutaneous lymphomas 2005: histological and molecular aspects. J Cutan Pathol 2005;32:647-74.

18. Willemze R, Jansen PM, Cerroni L, et al. Subcutaneous panniculitis-like T-cell lymphoma: definition, classification, and prognostic factors: an EORTC Cutaneous Lymphoma Group Study of 83 cases. Blood 2008;111:838-45.

19. Massone C, Chott A, Metze D, et al. Subcutaneous, blastic natural killer (NK), NK/Tcell, and other cytotoxic lymphomas of the skin: a morphologic, immunophenotypic, and molecular study of 50 patients. Am J Surg Pathol 2004;28:719-35. 
20. Weenig RH, Ng CS, Perniciaro C. Subcutaneous panniculitis-like T-cell lymphoma: an elusive case presenting as lipomembranous panniculitis and a review of 72 cases in the literature. Am J Dermatopathol 2001;23:206-15.

21. Magro CM, Crowson AN, Kovatich AJ, et al. Lupus profundus, indeterminate lymphocytic lobular panniculitis and subcutaneous T-cell lymphoma: a spectrum of subcuticular T-cell lymphoid dyscrasia. J Cutan Pathol 2001;28:235-47.

22. Pincus LB, LeBoit PE, McCalmont TH, et al. Subcutaneous panniculitis-like T-cell lymphoma with overlapping clinicopathologic features of lupus erythematosus: coexistence of 2 entities? Am J Dermatopathol 2009;31:520-6.

23. Magro CM, Crowson AN, Byrd JC, et al. Atypical lymphocytic lobular panniculitis. J Cutan Pathol 2004;31:300-6.

24. Massone C, Kodama K, Salmhofer W, et al. Lupus erythematosus panniculitis (lupus profundus): clinical, histopathological, and molecular analysis of nine cases. J Cutan Pathol 2005;32:396-404.

25. Kutzner H, Kerl H, Pfaltz MC, et al. CD123-positive plasmacytoid dendritic cells in primary cutaneous marginal zone B-cell lymphoma: diagnostic and pathogenetic implications. Am J Surg Pathol 2009;33:1307-13.

26. Kempf W, Kerl H, Kutzner H. CD123-positive plasmacytoid dendritic cells in primary cutaneous marginal zone B-cell lymphoma: A crucial role and a new lymphoma paradigm. Am J Dermatopathol 2011;32:194-6. 
Figure legends

Figure 1. Biopsy specimen from the subcutaneous nodule. At scanning magnification, a dense subcutaneous infiltrate with predominant involvement of the lobules can be recognized.

Figure 2. Biopsy specimen from the subcutaneous nodule. Lymphocytes are small, with occasional medium sized cells showing mild nuclear pleomorphism. Note rimming of lymphocytes around adipocytes (A, B). Admixture of plasma cells in the infiltrate can be seen (C)

Figure 3. Biopsy specimen from the subcutaneous nodule. Immunohistochemical staining for CD8 (A), beta F1 (B), CD138 (C) and CD123 (D). 
Figure 1

Click here to download high resolution image

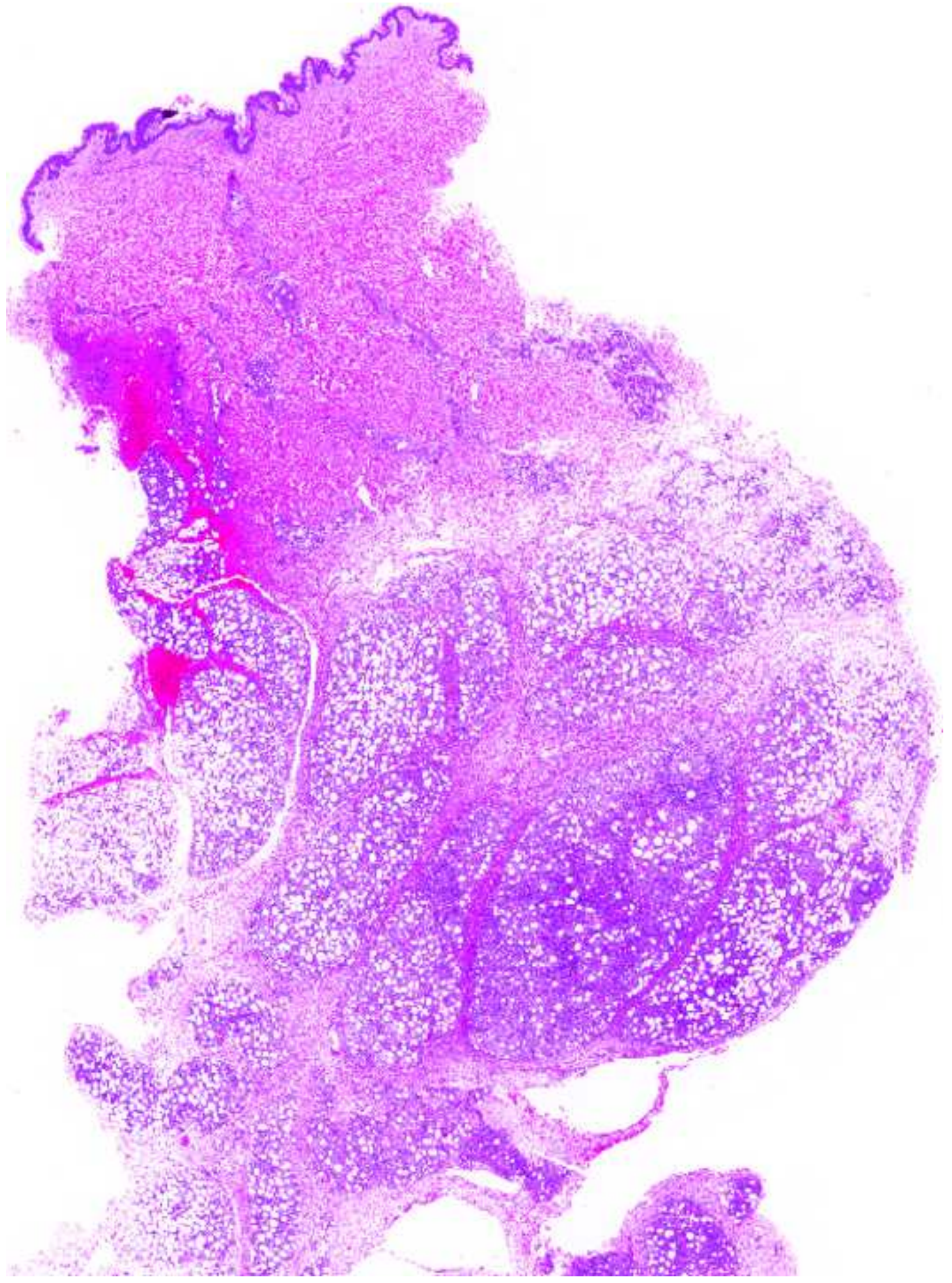


Figure 2

Click here to download high resolution image
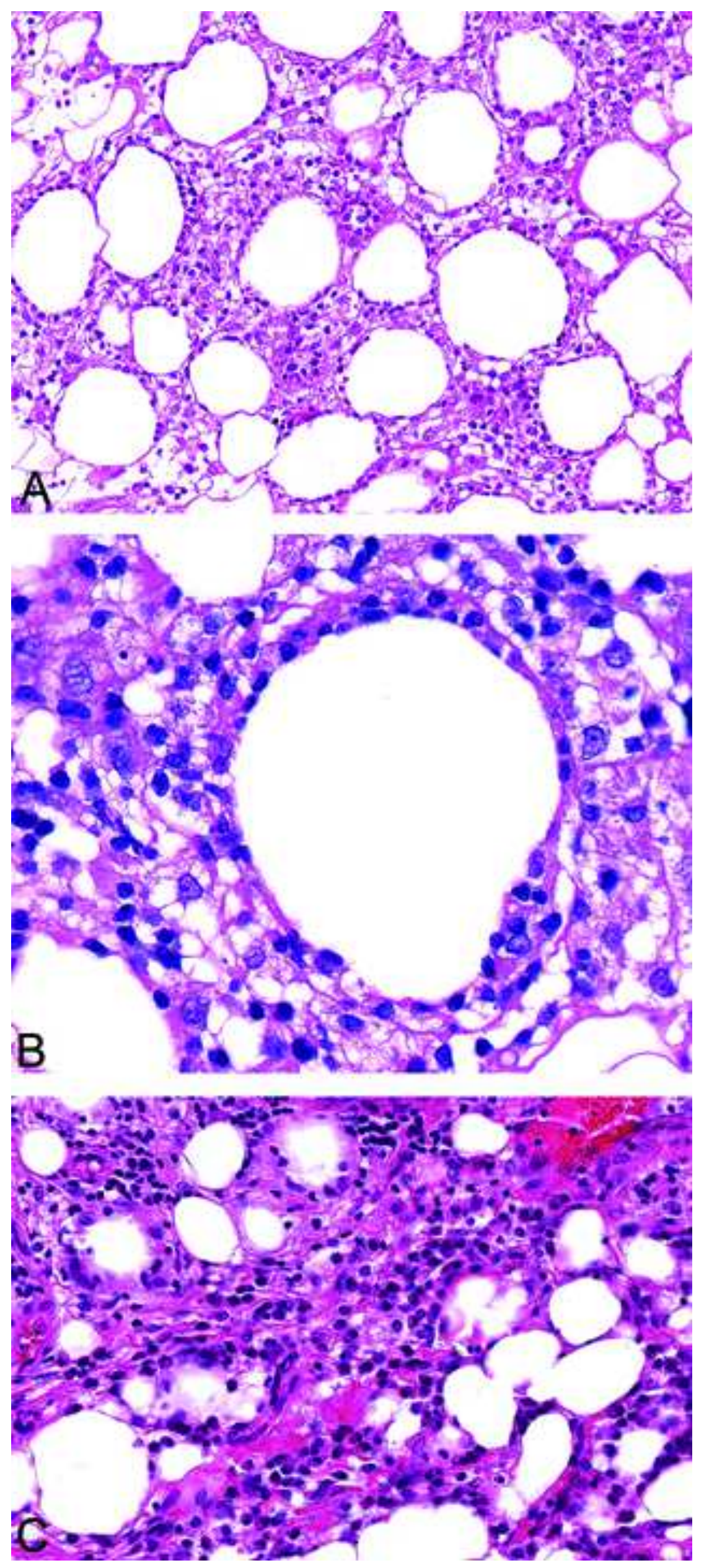


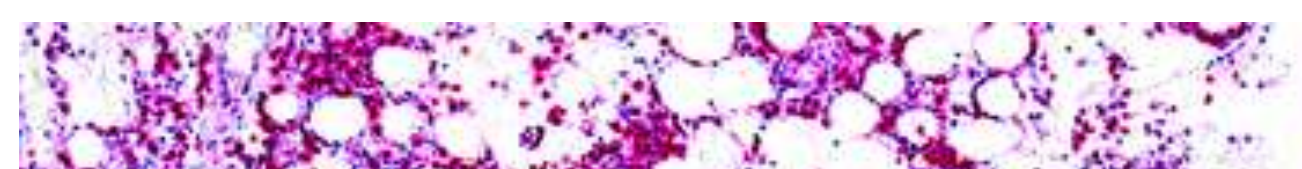

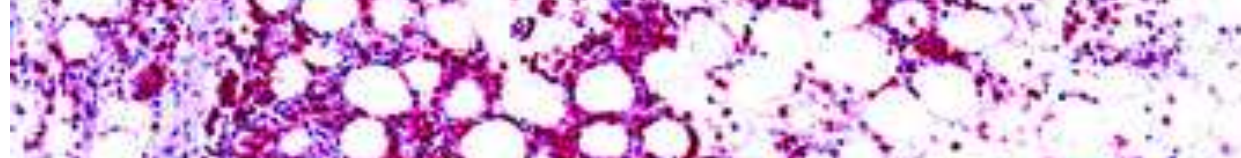

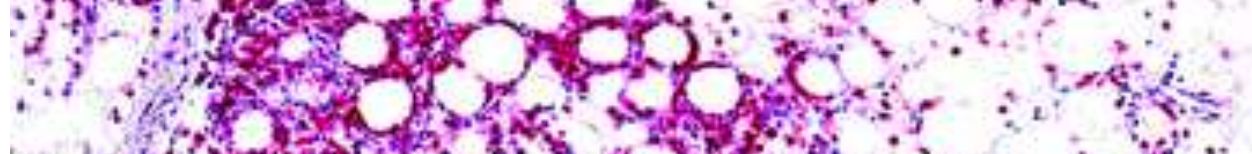
$101,1$. 5.

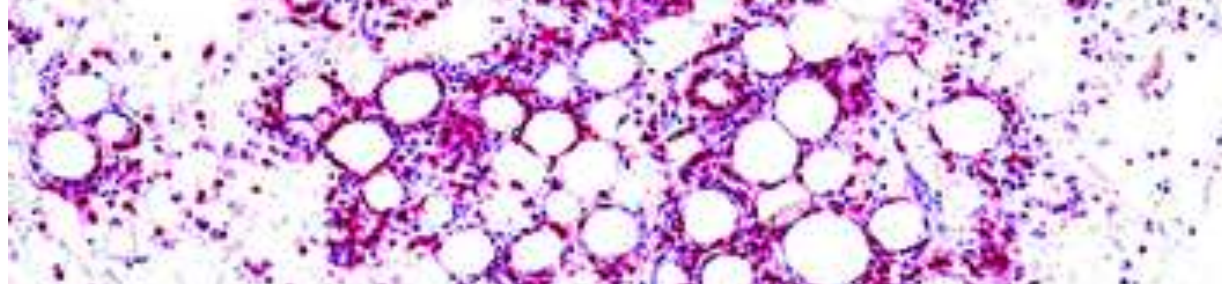

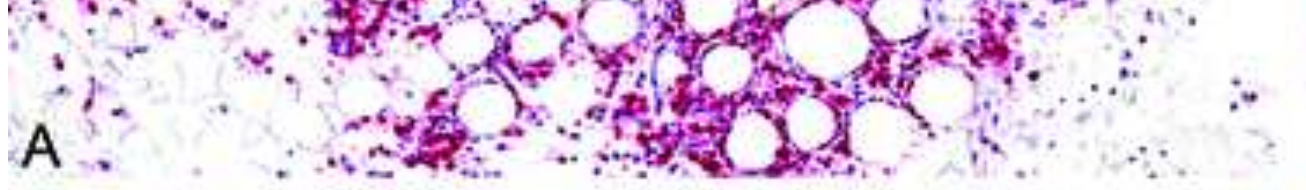

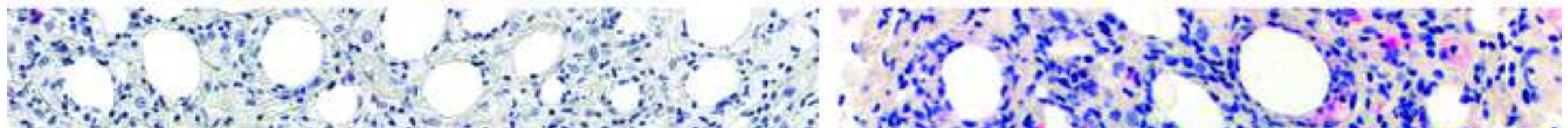

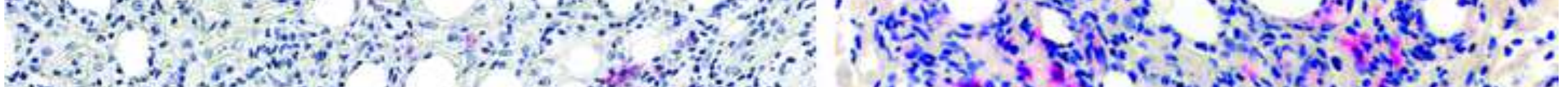

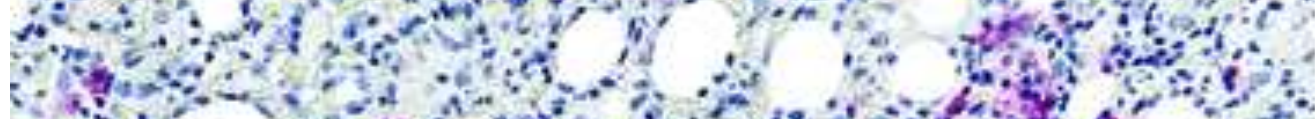
an fis

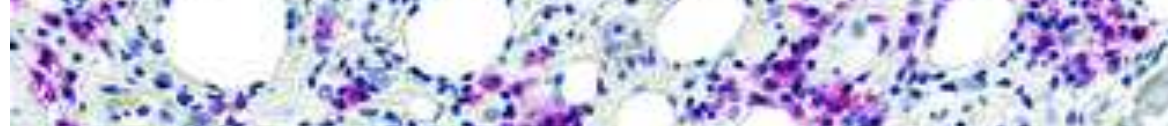

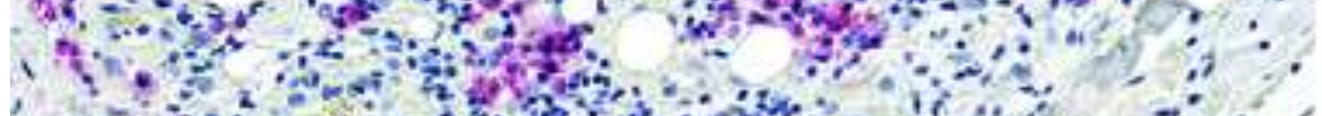

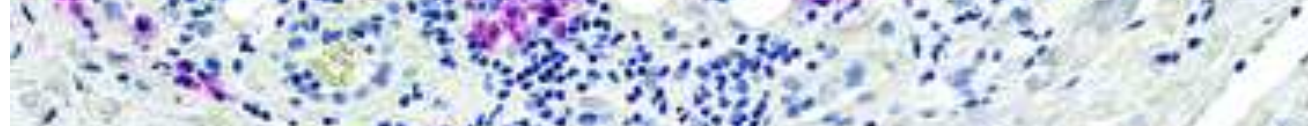
C

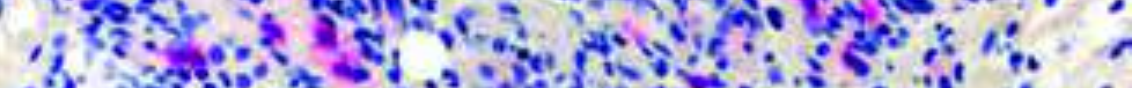
is. , ofe

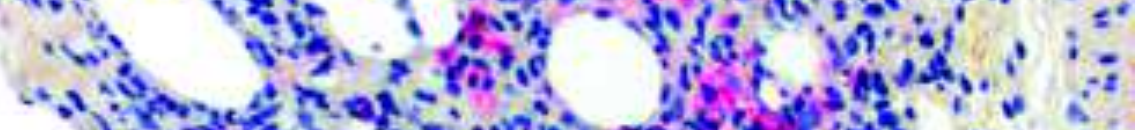

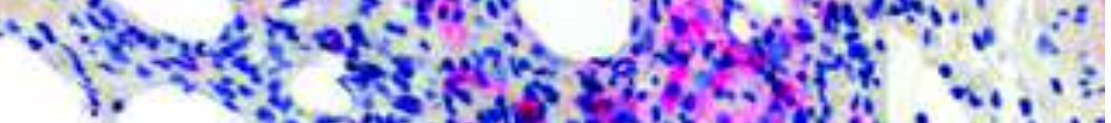
ond

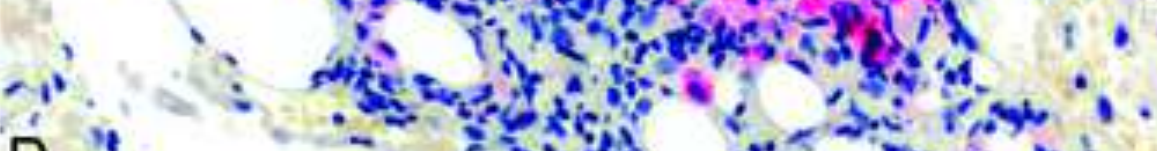

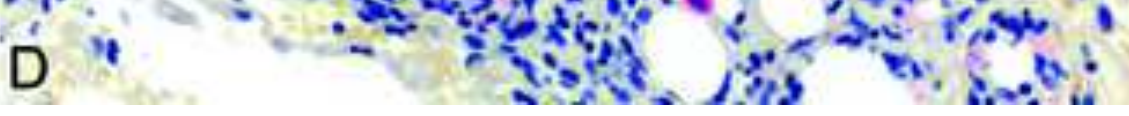


Click here to download LWW Copyright Transfer and Disclosure Form: Borrelia panniculitis DK.pdf

*LWW Copyright Transfer and Disclosure Form

$\sqrt{2}$

(1)

(1)

(1) (1) (1) -

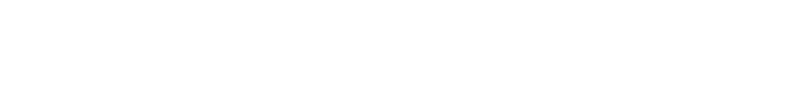

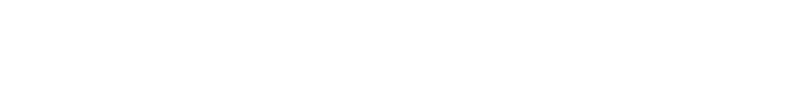


Click here to download LWW Copyright Transfer and Disclosure Form: Borrelia panniculitis WK.pdf

*LWW Copyright Transfer and Disclosure Form 